\title{
Microvascular anatomy of the cerebellar parafloccular perforating space
}

\author{
Pablo Sosa, MD, ${ }^{1}$ Manuel Dujovny, MD, ${ }^{2}$ Ibe Onyekachi, BS, ${ }^{2}$ Noressia Sockwell, BS, ${ }^{2}$ \\ Fabián Cremaschi, MD, ${ }^{1}$ and Luis E. Savastano, MD ${ }^{3}$
}

\begin{abstract}
'Department of Neuroscience, Clinical and Surgical Neurology, School of Medicine, National University of Cuyo, Mendoza, Argentina; ${ }^{2}$ Departments of Neurosurgery and Electrical Engineering, Wayne State University, Detroit; and ${ }^{3}$ Department of Neurosurgery, University of Michigan, Ann Arbor, Michigan
\end{abstract}

\begin{abstract}
OBJECTIVE The cerebellopontine angle is a common site for tumor growth and vascular pathologies requiring surgical manipulations that jeopardize cranial nerve integrity and cerebellar and brainstem perfusion. To date, a detailed study of vessels perforating the cisternal surface of the middle cerebellar peduncle-namely, the paraflocculus or parafloccular perforating space-has yet to be published. In this report, the perforating vessels of the anterior inferior cerebellar artery (AICA) in the parafloccular space, or on the cisternal surface of the middle cerebellar peduncle, are described to elucidate their relevance pertaining to microsurgery and the different pathologies that occur at the cerebellopontine angle.

METHODS Fourteen cadaveric cerebellopontine cisterns (CPCs) were studied. Anatomical dissections and analysis of the perforating arteries of the AICA and posterior inferior cerebellar artery at the parafloccular space were recorded using direct visualization by surgical microscope, optical histology, and scanning electron microscope. A comprehensive review of the English-language and Spanish-language literature was also performed, and findings related to anatomy, histology, physiology, neurology, neuroradiology, microsurgery, and endovascular surgery pertaining to the cerebellar flocculus or parafloccular spaces are summarized.
\end{abstract}

RESULTS A total of 298 perforating arteries were found in the dissected specimens, with a minimum of 15 to a maximum of 26 vessels per parafloccular perforating space. The average outer diameter of the cisternal portion of the perforating arteries was $0.11 \pm 0.042 \mathrm{~mm}$ (mean $\pm \mathrm{SD}$ ) and the average length was $2.84 \pm 1.2 \mathrm{~mm}$. Detailed schematics and the surgical anatomy of the perforating vessels at the CPC and their clinical relevance are reported.

CONCLUSIONS The parafloccular space is a key entry point for many perforating vessels toward the middle cerebellar peduncle and lateral brainstem, and it must be respected and protected during surgical approaches to the cerebellopontine angle.

http://thejns.org/doi/abs/10.3171/2015.2.JNS142693

KEY WORDS cerebellum; cerebellopontine cistern; cerebellopontine angle; anterior inferior cerebellar artery; posterior inferior cerebellar artery; perforating vessels; parafloccular perforating space; middle cerebellar peduncle; anatomy

$\mathrm{T}$ HE surgical anatomy of the cerebellopontine angle (CPA) is complex and challenging. The cerebellopontine cistern (CPC) lies in the CPA between the brainstem, cerebellum, and petrous portion of the temporal bone and is crossed by multiple delicate nerves and small vessels directed toward the cerebellum and highly eloquent portions of the brainstem. This region often witnesses vascular pathology and tumors, leading to lengthy cerebellar retraction, dissection, and the use of bipolar coagulation that jeopardizes the integrity of cranial nerves (CNs) and cerebellar and brainstem perfusion. The cister- nal surface of the middle cerebellar peduncle lateral to the cerebellar flocculus - namely, the paraflocculus or parafloccular perforating space - is particularly susceptible to the abovementioned surgical manipulation from a retrosigmoid approach, which is the workhorse approach for CPA lesions. The importance of this small but key area in the cerebellopontine interface was recognized in a classic article by David and Askenasy in the $1930 \mathrm{~s},{ }^{14}$ and previously published articles have described its topographic relationship to the major branches of the anterior inferior cerebellar artery (AICA) and posterior inferior cerebellar

ABBREVIATIONS AICA = anterior inferior cerebellar artery; $\mathrm{CN}=$ cranial nerve; $\mathrm{CPA}=$ cerebellopontine angle; $\mathrm{CPC}=$ cerebellopontine cistern; $\mathrm{PICA}=$ posterior inferior cerebellar artery; SCA = superior cerebellar artery.

SUBMITTED November 25, 2014. ACCEPTED February 25, 2015.

INCLUDE WHEN CITING Published online September 4, 2015; DOI: 10.3171/2015.2.JNS142693. 
artery (PICA) ${ }^{19,21,34,42,44}$ However, a detailed study of the perforating vessels entering the parafloccular space has not yet been published. Here, we review the microsurgical anatomy of the CPC and describe in detail the vessels that perforate the parafloccular space and distribute within the lateral pons and deep cerebellum. It is our expectation that this study will add knowledge to the microanatomy of the CPA and help decrease morbidity and mortality from surgical procedures involving this region. ${ }^{6}$

\section{Methods}

A search of the English- and Spanish-language literature was performed using the PubMed, BioMed, and Google Scholar scientific databases using the following key indexing terms: cerebellopontine angle, cerebellar flocculus, cerebellar paraflocculus, parafloccular space, brainstem perforating vessels, and anteroinferior cerebellar artery, in combination with anatomy, histology, physiology, neurology, neuroradiology, microsurgery, endovascular surgery, surgical complications, and stroke. Then, 7 macroscopically normal brains were harvested from adult human cadavers without known histories of stroke, dementia, malignancy, trauma, or neurosurgical intervention. The specimens were cleaned with saline solution and then were fixed using $2 \%$ formaldehyde solution. Next, the 7 cerebellums were isolated, the intradural vertebral arteries were catheterized using appropriately sized catheters, and the basilar arteries were ligated distally to the origin of the AICA and proximally to the basilar bifurcation. The formaldehyde solution within the vasculature was rinsed with normal saline, and red latex was used for arterial filling. A Wild M5A surgical microscope (Wild Heerbrugg) was used for dissections using 6-12× magnification. A total of 14 CPCs were dissected and subdivided into the superior, middle, and inferior cisternal portions in order to organize the anatomical analysis. The arachnoid of the CPC was opened under the surgical microscope utilizing the immersion technique, and the foramina of Luschka were identified. The lateral pontine $\left(a_{2}\right)$ and flocculopeduncular $\left(a_{3}\right)$ segments of the AICAs and the tonsillomedullary $\left(\mathrm{p}_{3}\right)$ and telovelotonsillar $\left(\mathrm{p}_{4}\right)$ segments of the PICAs ${ }^{53}$ were freed of the arachnoid, and the perforating vessels to the paraflocculus space were examined. Specifically, we measured the number, origin from the main vessel, outer diameter, length, branching pattern, and penetrating points in the paraflocculus. High-resolution images of the perforating arteries were obtained with a digital camera (DSC W330 14 MPX; Sony) attached to the microscope. Pictures were drawn to match the statistical analysis of the sample with photos of the dissections. Scanning electron microscopy (JSM-6610LV; JOEL) was also performed to study the microscopic features of the surface of the paraflocculus space. Then, digital pictures were processed using ImageJ software (National Institutes of Health) in order to measure the outer diameter of the perforating vessels. The accuracy of the measurements was confirmed by applying scanning electron microscopy to half of the specimens, which revealed good correlation between both techniques.

To obtain high-quality images in order to highlight the relationship between the perforating arteries and veins at the CPC, an additional head was harvested at the neck and perfused with $2 \%$ formaldehyde solution. It was then perfused with red latex via both carotid arteries and both vertebral arteries, and with blue latex via both internal jugular veins. The brain was then harvested, the CPC was dissected, and high-resolution images of the perforating vessels were obtained using a digital camera. Finally, an additional cadaveric brain was harvested, and intraarterial injections of red latex into the AICA and blue latex into the PICA were performed to identify AICA-PICA anastomosis and dual perfusion over the flocculus and paraflocculus. The cadaveric specimens were obtained from the Department of Anatomy at the Medical School of the National University of Cuyo and the Anatomical Donation Program of the University of Michigan, and all procedures adhered to institutional guidelines and approved protocols.

\section{Results}

\section{The CPC and Subdivisions}

As described by Rhoton, ${ }^{52}$ the CPC lies between the anterolateral surface of the pons and cerebellum and the arachnoid membrane that faces the petrous bone and is contained superiorly by the lateral pontomesencephalic membrane, inferiorly by the lateral pontomedullary membrane, medially by the anterior pontine membrane, and extends laterally along the cerebellopontine fissure. To focus our dissection on the region of interest and organize our results, we subdivided the CPC into superior, middle, and inferior cisternal portions (Fig. 1). The superior cisternal portion extends from the lateral pontomesencephalic membrane superolaterally, the anterior pontine membrane medially, and a transversal line (superior cisternal line) that extends from the horizontal cerebellar fissure and passes immediately caudal to the apparent origin of the trigeminal nerve inferiorly. Within this portion we consistently found the superior cerebellar artery (SCA), branches of the vein of the cerebellopontine fissure, the transverse pontine vein, trigeminal $\mathrm{CN}$, and the medial part of the superior limb of the superior cerebellopontine fissure (Fig. 1). The neural structures within this portion were largely perfused by the SCA branches. The middle cisternal portion extended from the superior cisternal line to a transversal line (inferior cisternal line) that extends from the cerebellar horizontal fissure to the inferior edge of the vestibulocochlear nerve. Within this portion, we found facial and vestibulocochlear nerves, a vein of the middle cerebellar peduncle, a vein of the cerebellomedullary fissure, and the AICA and its branches. Some of these branches had many perforating branches that will be described later. Other structures found in the middle portion were the cerebellar flocculus and paraflocculus (i.e., the cisternal surface of the middle cerebellar peduncle), and the superior cerebellopontine fissure. Finally, the inferior cisternal portion extended caudally from the inferior cisternal line to the lateral pontomedullary membrane. This segment contained a small part of the cerebellar flocculus, the foramen of Luschka, the inferior limb of the cerebellopontine fissure, branches of the vein of cerebellopontine 

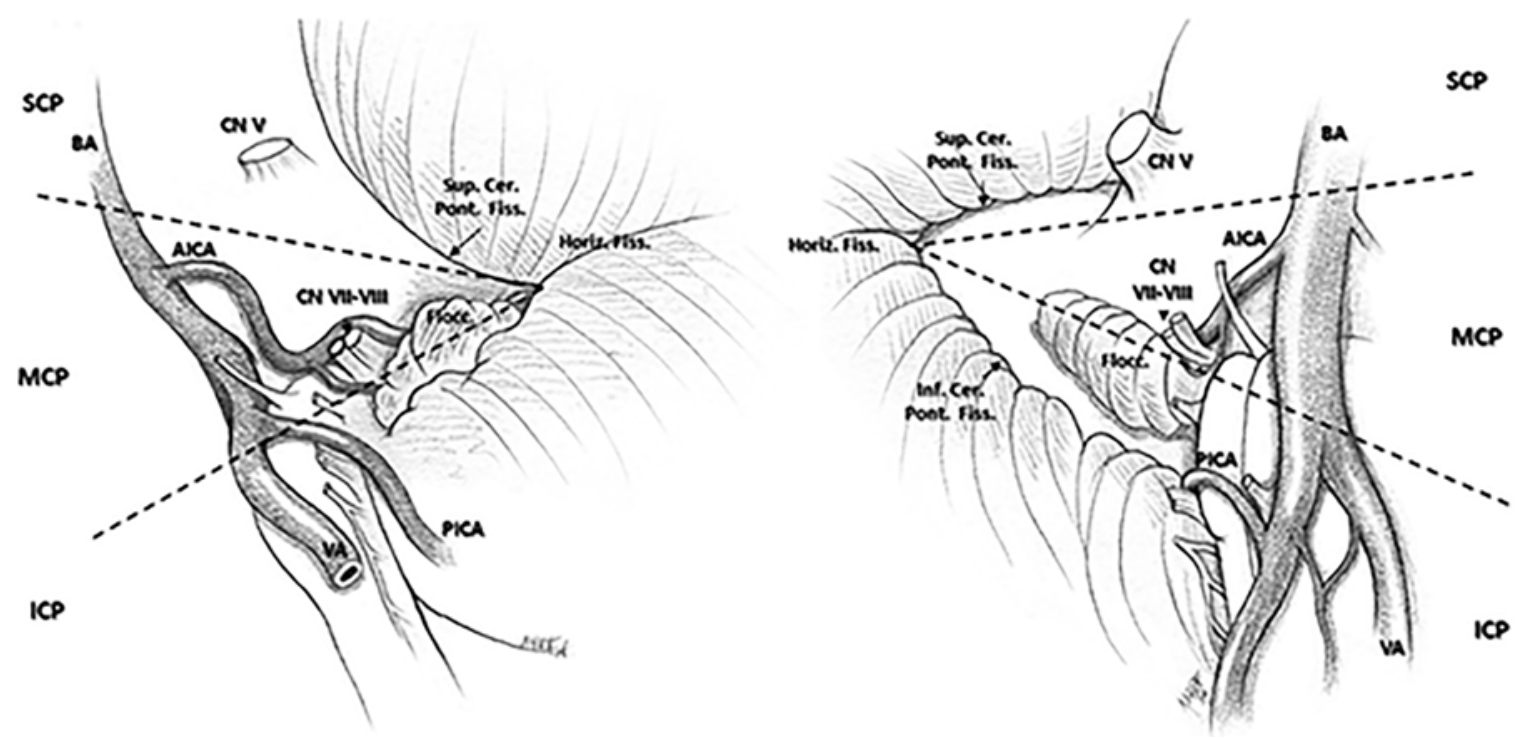

FIG. 1. Lateral (left) and anterior (right) views of the CPCs subdivided into superior, middle, and inferior portions. Note that distal AICA and PICA segments were not drawn. BA = basilar artery; Flocc. $=$ flocculus; Horiz. Fiss. $=$ horizontal fissure; Inf. Cer. Pont. Fiss. = inferior cerebellopontine fissure; ICP = inferior cisternal portion; $\mathrm{MCP}=$ middle cisternal portion; $\mathrm{SCP}=$ superior cisternal portion; Sup. Cer. Pont. Fiss. = superior cerebellopontine fissure; VA = vertebral artery. Copyright Megan Foldenauer. Published with permission.

fissure, branches of the AICA and perforating arteries, and, in some cases, the PICA and its branches. Our dissections were focused on the cerebellar flocculus and parafloccular space within the middle and inferior cisternal portion of the CPC.

\section{Cerebellar Parafloccular Space and Flocculus}

The parafloccular perforating space was defined as the triangular-shaped cisternal surface of the middle cerebellar peduncle between the superior and inferior cerebellopontine fissures that extends laterally to the fissure apex and wraps medially over the flocculus (Fig. 2). The cerebellar flocculi were consistently found to have an elliptical shape over the anterior surface of the cerebellum facing the CPC, and were limited by the inferior cerebellopontine fissure inferiorly, the superior cerebellopontine fissure superiorly, and the pons medially. The average transverse and vertical dimensions were $7.5 \mathrm{~mm}$ and $12 \mathrm{~mm}$, respectively. The flocculi were related superiorly with CNs VII and VIII and inferiorly with the foramen of Luschka and the lateral recess of the fourth ventricle.

The flocculi were mainly perfused by the cortical branches of the AICA with occasional minor distal PICA contributions extending from the choroid plexus though the foramen of Luschka (Fig. 3 left). The paraflocculi were found to be irrigated entirely by small perforating branches of the AICA (Fig. 3 right). The distinct angioarchitecture encountered in our dissections was further elucidated by the electron microscopy scans, which confirmed a predominant cortical pattern of the arteries over the flocculi (i.e., vascular arborization over the cortical surface before parenchyma penetration) and deep perforating vessels in the paraflocculus space (i.e., vascular arborization within the parenchyma after the penetration of the larger vessels) (Fig. 4).

\section{Perforating Vessels of the AICA}

A total of 298 perforating arteries (15-26 per specimen) from the lateral pontine and flocculopeduncular segments of the AICA were found in 14 CPCs, entering the superior and inferior cerebellopontine fissure and the parafloccular perforating space. The outer diameter of the perforating arteries was $0.11 \pm 0.042 \mathrm{~mm}$ (mean $\pm \mathrm{SD}$ ), and the length was $2.84 \pm 1.2 \mathrm{~mm}$. We found multiple branching patterns of arteries entering the parafloccular perforating space from their AICA origin. Of the 298 perforating arteries found, we identified 48 small vessels penetrating the flocculus directly from the AICA without branches. The remaining 250 parafloccular perforating vessels branched from the common trunk(s) emerging from the AICA: 81 were subbranches from a single common trunk, 52 were from 2 trunks, 46 were from 3 trunks, and 71 were subbranches from more than 3 main trunks (Table 1).

The most frequent penetration point (169 vessels) was found to be the lateral third of the superior cerebellopontine fissure at the junction of the superior and inferior cerebellopontine fissures (Fig. 5). We found 91 perforating vessels in the middle and medial thirds of the superior cerebellopontine fissure, and 11 vessels entering at the lateral third of the inferior cerebellopontine fissure (Fig. 6). We also identified occasional perforating vessels in the axilla of the facial and vestibulocochlear nerves at the brainstem (Fig. 7).

In 194 of 298 cases, the penetration points into the brainstem of the perforating arteries, especially along the superior cerebellopontine fissure, were hidden underneath the vein of the cerebellopontine fissure and the vein of the middle cerebellar peduncle. These veins receive the deep drainage of the area supplied by the perforating arteries and emerge from the brainstem in the same region as the entry point of the perforating arteries (Fig. 8). In many 


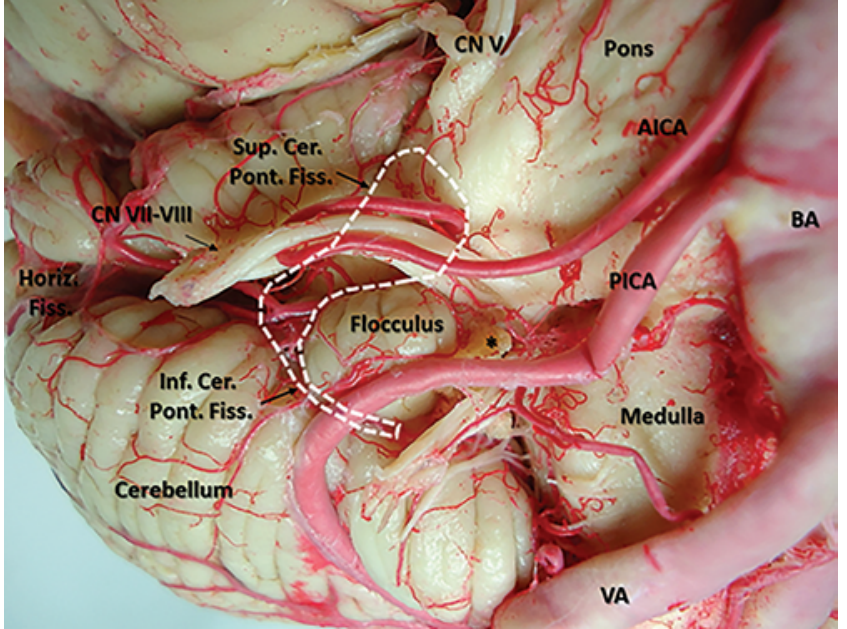

FIG. 2. Anterolateral view of the right parafloccular perforating space at the CPA. The parafloccular perforating space is outlined by the dotted line. Note the Y-shaped bifurcation of the horizontal fissure (Horiz. Fiss.) into the superior cerebellopontine fissure (Sup. Cer. Pont. Fiss.) and inferior cerebellopontine fissure (Inf. Cereb. Pont. Fiss.). Also note the origin of right AICA and PICA from the basilar artery (BA). The AICA loops between the facial and vestibulocochlear CNs (CN VII-VIII). The choroid plexus (asterisk) extends from the lateral recess of the fourth ventricle. $V A=$ vertebral artery. Figure is available in color online only.

cases, it was necessary to mobilize and/or resect the veins in order to observe the penetration points of the arteries.

In our study, no perforating arteries of the tonsillomedullary $\left(\mathrm{p}_{3}\right)$ or telovelotonsillar $\left(\mathrm{p}_{4}\right)$ segments of the PICA were found to enter the paraflocculi. However, in some of our dissections, we found distal terminal branches from the telovelotonsillar segment of the PICA $\left(\mathrm{p}_{4}\right)$ directed to the tela choroidea and choroid plexus of the fourth ventricle that anastomosed with the AICA branches and distributions over the flocculi (Fig. 9).

\section{Discussion}

\section{Literature Review of the Perforating Vessels From the AICA}

Since the pioneering work of Thomas Willis in the

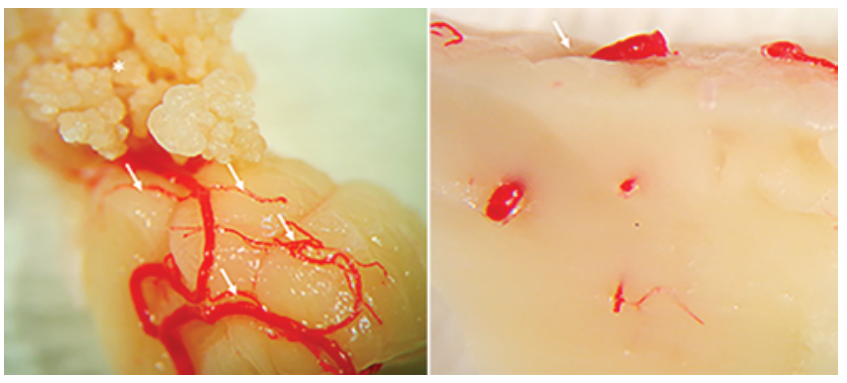

FIG. 3. Left: Angioarchitecture of the flocculus with the classic cortical pattern consisting of superficial arborization of the AICA branches over the flocculus (arrows). Note the intimate relationship of the flocculus with the choroid plexus (asterisk). Right: Angioarchitecture of the parafloccular perforating space. Note the perforating pattern of the arteries entering the parenchyma (arrow) on the axial section though the middle cerebellar peduncle (16x magnification). Figure is available in color online only.
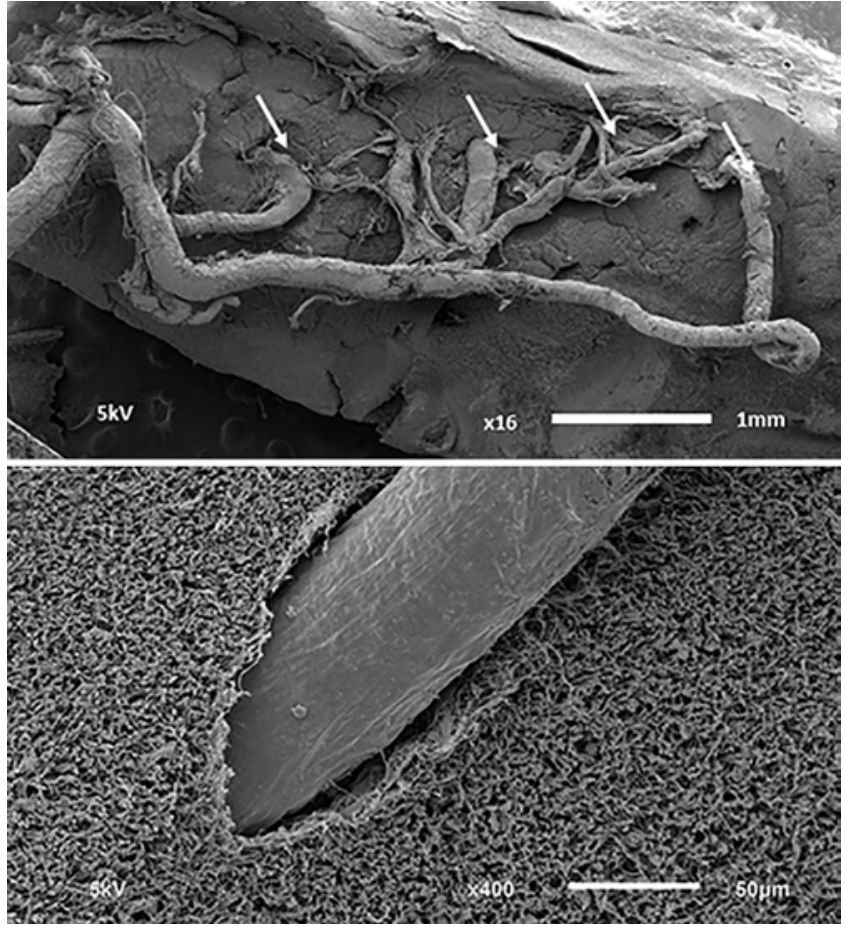

FIG. 4. Scanning microscopy images showing numerous perforating branches arising from a single trunk of the AICA at the surface of the paraflocculus (scale $=1 \mathrm{~mm} ; 16 \times$ magnification) (upper) penetrating into the middle cerebellar peduncle (scale $=50 \mu \mathrm{m} ; 400 \times$ magnification) (lower).

17 th century on the anatomy of the brain vessels, extensive research has been done and we now have an overall thorough knowledge of the surface cerebrovascular anatomy, especially the microsurgical anatomy of the supratentorial arteries. ${ }^{6,11,12,15,18,26,32,37,43,45-47,49}$ The importance of these numerous but small vessels was stated more than 50 years ago by Elizabeth Crosby at the University of Michigan, ${ }^{13}$ further elucidated by Rhoton, ${ }^{42,52}$ Duvernoy, ${ }^{46}$ and Yaşargil ${ }^{64}$ who described a "map of brainstem perforation zones" and a region known as the basal cerebellar group. Yaşargil described this group as a "ring" composed by the branches of the AICA, SCA, and basilar artery. He commented that the basal cerebellar group extends into the horizontal cerebellar fissure, lateral to the cerebellar flocculus and paraflocculus, but he did not describe the characteristics of the perforating branches in the parafloccular region. ${ }^{64}$

To the best of our knowledge, the only article in the literature that describes with some detail the perforating vessels arising from the AICA was published by Shrontz et al. in $1986 .{ }^{59}$ According to their description, as the AICA extends from the basilar artery in the lateral and caudal directions, the second segment of the AICA $\left(\mathrm{a}_{2}\right.$, or the lateral pontine segment) courses laterally and comes in close proximity to CN VII at the lateral portion of the cerebellar flocculus. The perforating branches in this segment originate from the initial $10 \mathrm{~mm}$ of the vessel after the CN VII crosses over the AICA. There are few perforating vessels in the $10-\mathrm{mm}$ segment proximal to the CN VII crossover. The third segment of the AICA, between CN VII and its 
TABLE 1. Characteristics of the cerebellar perforating arteries of the parafloccular space

\begin{tabular}{cccc}
\hline $\begin{array}{c}\text { Cerebellum } \\
\text { No. }\end{array}$ & $\begin{array}{c}\text { Perforating Arteries } \\
\text { per Cerebellum } \\
\text { (Right/Left Side) }\end{array}$ & $\begin{array}{c}\text { Length in mm } \\
\text { (mean } \pm \text { SD) }\end{array}$ & $\begin{array}{c}\text { Outer Diameter } \\
\text { in mm } \\
\text { (mean } \pm \text { SD) }\end{array}$ \\
\hline 1 & $19 / 17$ & $2.95 \pm 0.76$ & $0.096 \pm 0.036$ \\
\hline 2 & $20 / 25$ & $2.79 \pm 1.22$ & $0.1 \pm 0.035$ \\
\hline 3 & $26 / 15$ & $3.04 \pm 1.18$ & $0.1 \pm 0.03$ \\
\hline 4 & $25 / 21$ & $3.24 \pm 1.5$ & $0.12 \pm 0.04$ \\
\hline 5 & $22 / 24$ & $2.89 \pm 1.5$ & $0.096 \pm 0.031$ \\
\hline 6 & $19 / 26$ & $2.55 \pm 1.08$ & $0.11 \pm 0.037$ \\
\hline 7 & $16 / 23$ & $2.8 \pm 0.8$ & $0.12 \pm 0.028$ \\
\hline
\end{tabular}

termination at the cerebellar hemisphere, has the largest concentration of perforating branches in the initial $15 \mathrm{~mm}$ of its length. These results correlate well with our dissections, as we found a high number of perforating arteries from the postfacial AICA entering the neuraxis via the cerebellopontine fissure.

\section{Relevance of the Perforating Vessels}

The importance of the perforating vessels of the brainstem and the base of the brain and their potential for a catastrophic event if they became occluded or ruptured is currently well-known. ${ }^{1,15,27,33}$ As mentioned earlier, these small vessels have been the focus of extensive research in the past, but the microanatomy of the perforating vessels of the AICA at the parafloccular space still requires further elucidation. In the following paragraphs, we attempt to provide a correlation between the parafloccular perforating vessels found in our dissections with a wide spectrum of diseases involving the CPA and hindbrain strokes.

\section{Cerebellar and Brainstem Infarcts}

Kase et al. ${ }^{30}$ reported that cerebellar infarcts are rare, representing approximately $1.5 \%$ of strokes, but they can be potentially devastating and are often underdiagnosed due to the equivocal symptoms that can at times mimic labyrinthine diseases or gastrointestinal problems, such as ataxia, vertigo, and vomiting. ${ }^{40}$ Amarenco and colleagues ${ }^{2-4}$ published a series of articles focused on SCA, AICA, and PICA territory strokes. They stated that in PICA and SCA territory infarcts, the clinical signs are dominated by cerebellar infarction, while brainstem signs predominate in AICA strokes. A pure AICA infarct affects the lateral pons, middle cerebellar peduncle, and cerebellar flocculus, and neurological examination is remarkable for weakness of the proximal upper and lower extremities, facial weakness, dysarthria, dysmetria, vertigo, ataxia, horizontal nystagmus, hearing loss, contralateral decreased temperature, and pain sensation. The structures mainly damaged in these scenarios are the middle cerebellar peduncle and flocculus, with extension into the neighboring cerebellar lobules between the territories of the SCA and PICA. Roquer et al. in $1998^{54}$ presented a correlative study between neurological symptoms and findings on MRI in patients with AICA strokes using

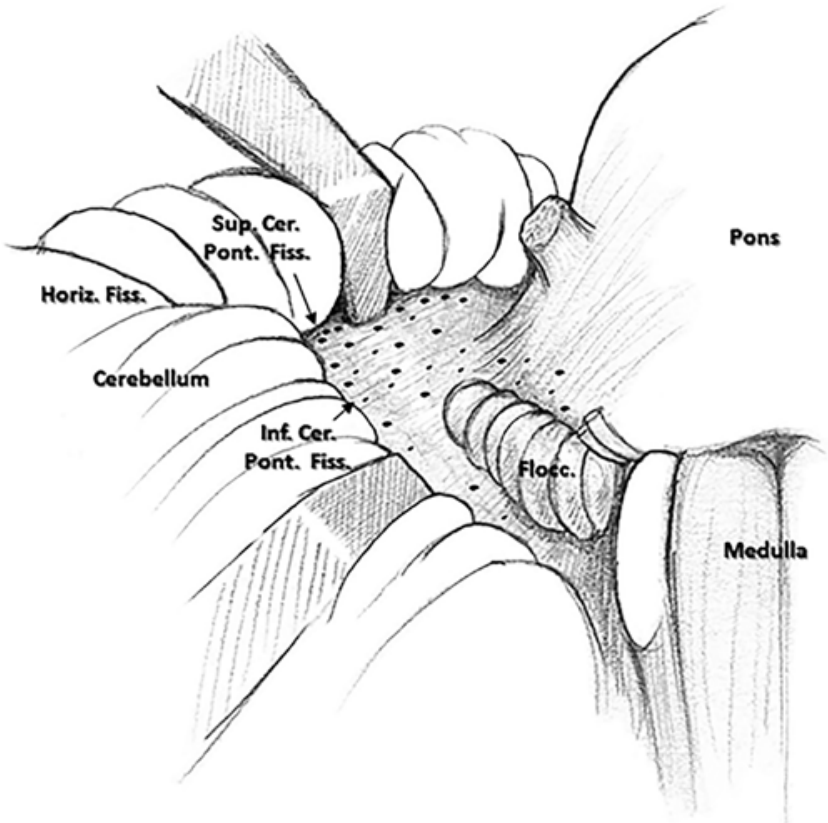

FIG. 5. Point of penetration of the perforating arteries of the AICA into the right parafloccular perforating space. Flocc. $=$ flocculus; Horiz. Fiss. $=$ horizontal fissure; Inf. Cer. Pont. Fiss. = inferior cerebellopontine fissure; Sup. Cer. Pont. Fiss. = superior cerebellopontine fissure. Copyright Megan Foldenauer. Published with permission.

the anatomical diagrams of Amarenco and Hauw. ${ }^{2}$ The middle cerebellar peduncle was the core of the affected territory in AICA strokes and was suggested as the radiological hallmark of this vascular insult. The flocculus and adjacent cerebellar white matter were not consistently affected, and were likely secondary to the heterogeneity of the areas supplied by AICA. In their article, Roquer et al..$^{54}$ stated that the proximal AICA supplies the lateral area of the pons, while the distal segment (when the vessel crosses the vestibulocochlear nerve) gives off many small arteries that supply the middle cerebellar peduncle and the lateral lower two-thirds of the pons. ${ }^{16,22,24,25,31}$

The middle cerebellar peduncle is located on the cisternal surface of the large peduncular mass, and if injured during surgery can result in ipsilateral ataxia, hypotonia, and dysmetria and cause a clinical scenario much like that seen in AICA stroke. ${ }^{51}$ These clinical features are most often encountered after aggressive surgical manipulation of the cerebellomesencephalic and pontocerebellar fissures, and are likely explained by our findings where a great number of the perforating arteries of the distal portion of the AICA supply the middle cerebellar peduncle through the parafloccular perforating space. However, complete AICA strokes are very rare after the resection of CPA tumors. A more commonly encountered scenario, mainly with large tumors, is partial or limited AICA syndrome with isolated diffusion changes in the ipsilateral cerebellar peduncle on postoperative MRI. The extent of cerebellar peduncle infarction varies from small focal lesions involving only one-third of the peduncle to diffuse defects spanning the full thickness of the peduncle. ${ }^{24}$ These patients generally present with dysmetria and gait imbalance, but 


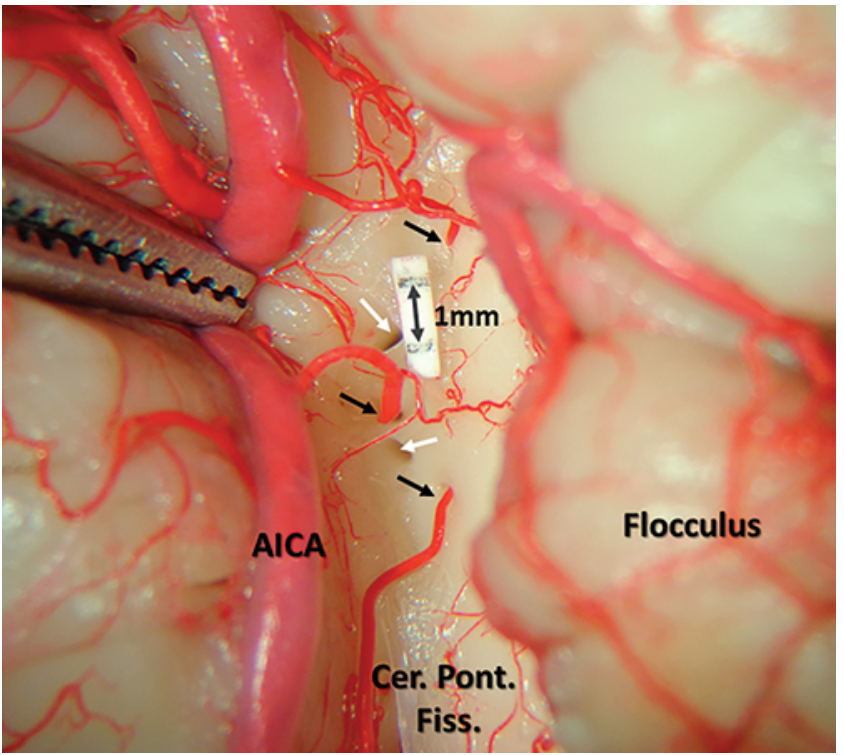

FIG. 6. Magnified view of the cerebellopontine fissure with the entry points of the perforating arteries of AICA into the parafloccular perforating space noted (black arrows). Note the small opening near the entry points of the perforating arteries, including the exit point of the deep vein tributaries to the vein of the cerebellopontine fissure (white arrows) (scale $=1 \mathrm{~mm}$, as shown by the double-headed arrow; 16 $\times$ magnification). Cer. Pont. Fiss. = cerebellar pontine fissure. Figure is available in color online only.

at times can have very subtle symptoms; therefore, the real incidence is probably underestimated. Our findings support the theory that limited AICA syndrome is likely secondary to surgical damage of the distal postfacial AICA perforating vessels directed to the parafloccular space, rather that venous insult or direct surgical trauma. In our dissections, these small perforating arteries branched into vessels destined to the vestibulocochlear nerve complex and the middle cerebellar peduncle, and therefore could be intimately related to the capsule of a vestibular schwannoma supplying both the neoplasm and the brain parenchyma and be very vulnerable to surgical injury.

\section{Arterial Aneurysms}

Aneurysms of the posterior fossa comprise about $8 \%$ to $15 \%$ of all intracranial aneurysms, with $0.5 \%$ to $1 \%$ occurring in the distal portion of the AICA and PICA. These are among the most difficult aneurysms to diagnose and treat, either by open or endovascular means. ${ }^{5,35}$ AICA aneurysms generally occur at the origin of this vessel at the basilar artery, but they can also occur distally at the CPA. ${ }^{50}$ Treating these distal AICA aneurysms is challenging and generally complicated by a new-onset neurological deficit that is likely secondary to ischemia in the brainstem, middle cerebellar peduncle, or CNs. Sarkar and Link ${ }^{58}$ reported a case of distal AICA aneurysm clipping with postsurgical increase in nystagmus and ataxia and findings on MRI of middle cerebellar peduncle stroke. Figueiredo et al. ${ }^{20} \mathrm{em}-$ phasized the importance of considering small perforating vessels during clip application to distal AICA aneurysms. In our study, we found 15 to 26 perforating vessels of the AICA entering the middle cerebellar peduncle through the parafloccular space. These vessels must be identified and protected during clip application to distal AICA aneurysms and revascularization procedures in the posterior circulation in order to prevent ischemic damage to the very eloquent middle cerebellar peduncle. Similarly, this explains the high rate of neurological complications with parent vessel occlusion during endovascular treatment of distal AICA aneurysms, which should only be considered when no other option is available. ${ }^{57}$

\section{Surgical Approach to CPA and Cerebellar Retraction}

Posterior fossa skull base surgery is challenging and associated with a high risk of morbidity and mortality. ${ }^{56}$ Multiple innovative and refined approaches have been developed over the past few decades in attempts to open the narrow angles of the skull base and safely navigate the crowded cisterns with many fragile neurovascular structures. This is particularly true for cerebrovascular pathology that is generally deep-seated and surrounded by critical neurovascular structures, where maintaining the integrity of the perforating vessels and achieving proximal control
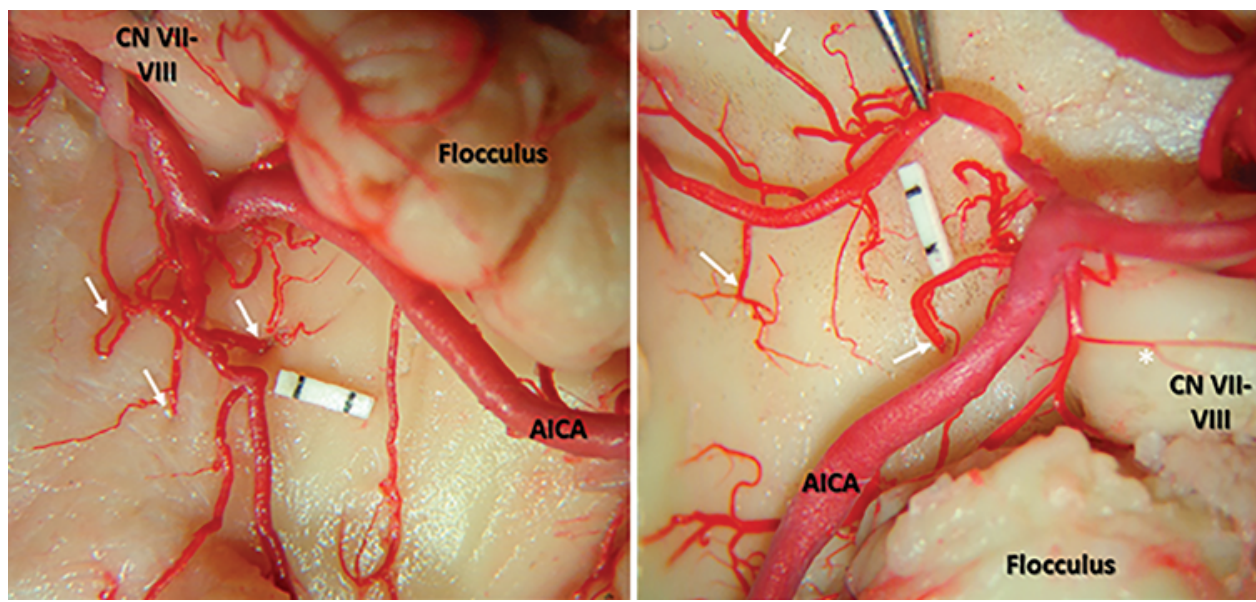

FIG. 7. Two views of numerous perforating arteries (arrows) into the paraflocculus within a few millimeters of the apparent exit point of the vestibulocochlear and facial nerves. Note the vasa nervorum (asterisk) to CNs VII-VIII originating from a perforating vessel (scale $=1 \mathrm{~mm} ; 12 \times$ magnification). Figure is available in color online only. 

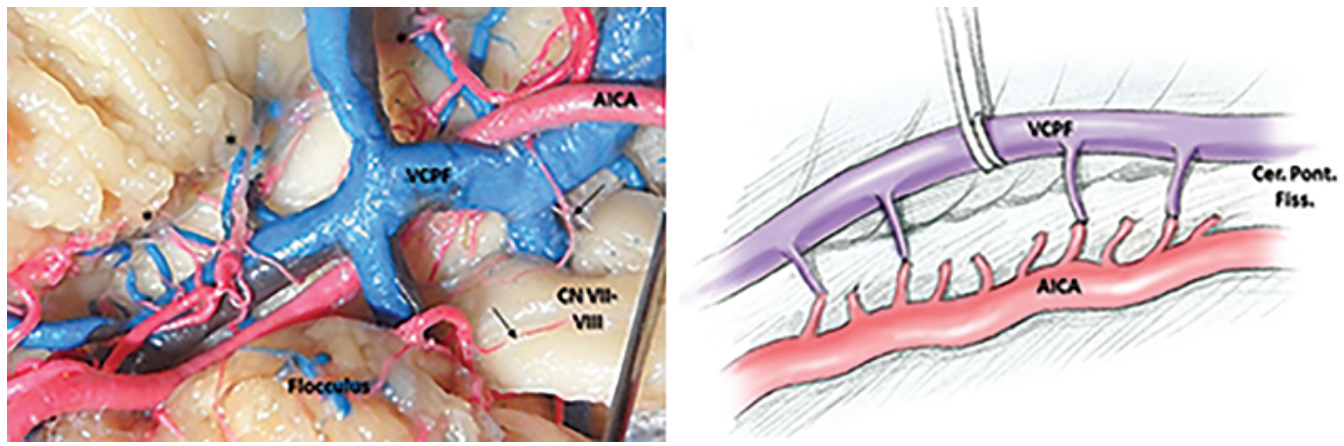

FIG. 8. Left: High-magnification image of the flocculus and caudal displacement of the vein of the cerebellopontine fissure (VCPF) reveal the intimate relationship between the perforating arteries and veins in this region (asterisks). Note the vasa nervorum (black arrows) to CNs VII-VIII originating from the perforating vessels. Right: Schematic drawing of the superior cerebellar fissure showing the proximity of the perforating arteries and veins to the lateral pons. Cer. Pont. Fiss. = cerebellopontine fissure. Right panel copyright Megan Foldenauer. Published with permission. Figure is available in color online only.

can be at times extremely challenging.? Brain retractors are widely used tools for improving the exposure of deepseated pathology in the posterior fossa, but their application is not always innocuous. Dujovny et al..$^{18}$ and Laha et al. ${ }^{37}$ documented retraction-related hemorrhage, ischemia, brain tissue deformity, and edema in approximately $10 \%$ of skull base surgeries. They correlated the type and severity of injury in relation to the surgical procedure performed, number of retractors, and the surgeon's experience and found an incidence of 3\% to $9 \%$ of postoperative retractorrelated neurological deficits. Retractor-related hemorrhages occurred in $8 \%$ of surgeries for aneurysms (the majority being posterior circulation aneurysms), with $22 \%$ having radiographically proven postoperative ischemia and $10.9 \%$ of neurological deficits attributed to a perforating artery injury generated by the retractor. Rosenørn and Diemer ${ }^{55}$ experimentally showed focal cerebral ischemia directly related to the use of brain retractors. Retraction of the flocculus and paraflocculus region during posterior fossa operations has been proven to contribute to increased mor- bidity and mortality, which could be potentially decreased by thorough knowledge of the perforating vessels in this region. ${ }^{33,37}$ Our findings suggest that direct pressure over the superior cerebellopontine fissure and medial third of the horizontal fissure must be avoided to decrease retractor-related strokes (Figs. 5 and 6). Ohue et al. ${ }^{48}$ mentioned that the branches of the SCA, AICA, and the vein of the cerebellopontine fissure often run in the horizontal fissure. These vessels should be preserved during dissection of the fissure using a retrosigmoid suprafloccular transhorizontal fissure approach. These vessels are key for cerebellum and brainstem perfusion and should be preserved as much as possible during dissection of the horizontal fissure. The perforating arteries and veins in this region can be potentially damaged by bipolar coagulation during surgery with the possibility of generating an arterial or venous infarct. ${ }^{17}$ In our dissection, the penetration points into the brainstem of the perforating arteries, especially along the superior cerebellopontine fissure, were hidden underneath the vein of the cerebellopontine fissure and the vein of the mid-
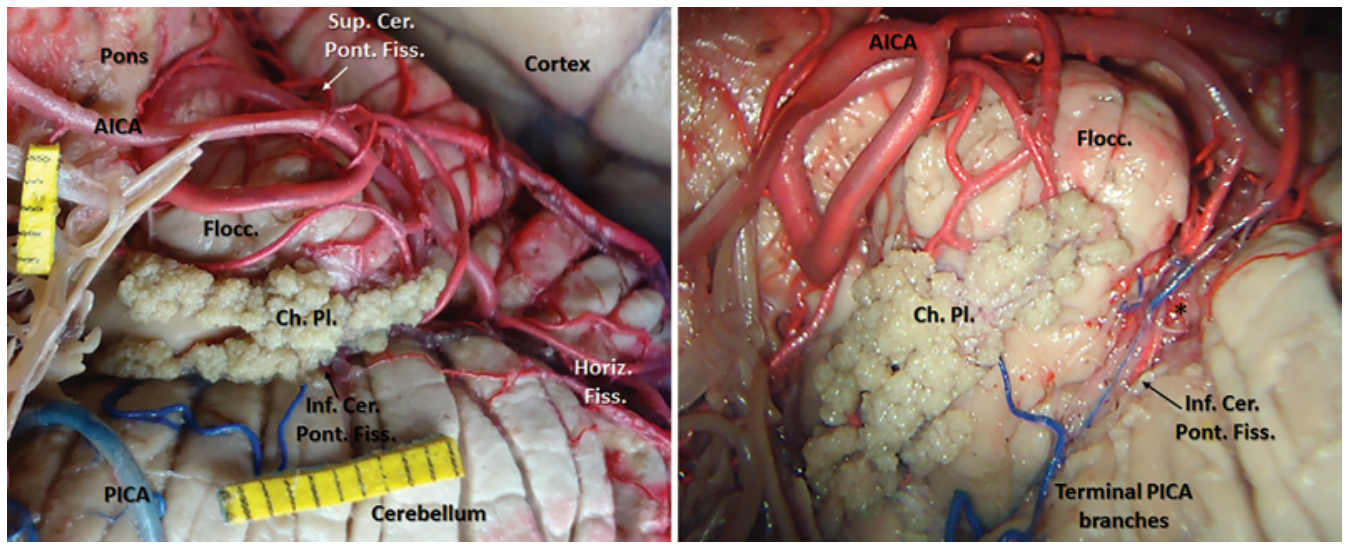

FIG. 9. AICA-PICA anastomosis. Left: Low magnification view of the left CPC reveals the relationship between the flocculus (Flocc.) and choroid plexus (Ch. PI.). The AICA is filled with red latex and the PICA with blue latex. Right: High-magnification image after dissecting and opening the inferior cerebellopontine fissure (Inf. Cer. Pont. Fiss.) shows the coexistence of red and blue latex (asterisk) secondary to anastomosis between the AICA's floccular branches with the PICA's distal choroid vessels (16x magnification). Horiz. Fiss. = horizontal fissure; Sup. Cer. Pont. Fiss. = superior cerebellopontine fissure. Figure is available in color online only. 
dle cerebellar peduncle, and it was frequently necessary to mobilize the veins in order to observe the penetration points of the arteries (Fig. 8).

\section{Tumors}

CPA tumors, such as meningiomas, schwannomas, epidermoids, metastases, and chordomas, can involve the perforating vessels of the AICA and PICA. ${ }^{10,61,62}$ Vestibular schwannomas are one of the most common intracranial tumors and constitute $90 \%$ of CPA lesions. Postsurgical ischemic complications are generally confined to the ipsilateral middle cerebellar peduncle ${ }^{29}$ and likely secondary to the loss of distal AICA ramifications or perforating vessels. ${ }^{24}$ Tumors in this area can compress, stretch, or completely incorporate the perforating vessels or their trunks from the AICA, ${ }^{12,39-41}$ and these vessels can be intimately related to the tumor capsule and supply both the neoplasm via the vasa nervorum and the middle cerebellar peduncle via the terminal perforating vessels, as demonstrated in our dissections.

\section{Neurovascular Decompressions}

The symptoms of trigeminal or glossopharyngeal neuralgia (somatic sensory), hemifacial spasm (somatic motor), tinnitus, vertigo (special sensory), and some cases of essential hypertension are thought to be caused by compression of $\mathrm{CN} \mathrm{V}$, VII, VIII, IX, or X and the medulla oblongata by the cerebellar arteries. Surgery in such cases is a valuable therapeutic option. , $20,23,26,29^{2}$

Hemifacial spasm is considered a reversible pathophysiological condition that is generally induced by pulsatile compression of the facial nerve root exit zone at the CPA, usually by the second portion of the AICA..$^{11,60}$ Microvascular decompression is a safe and definitive treatment for hemifacial spasm with proven long-term efficacy, but it is not a risk-free procedure and devastating brainstem infarctions, among other complications, have been reported in the literature. ${ }^{8}$ Nagatani et al. ${ }^{45}$ and Liang et al..$^{38}$ commented that appropriate facial nerve decompression from the AICA occasionally encounters interference from the perforating branches associated with this vessel and concluded that the perforating branches tend to be more frequent in AICA than PICA. Jo et al. ${ }^{28}$ and Kong and Park ${ }^{36}$ also commented on the difficulties of creating an adequate space between the compressing vessel and the nerve during microvascular decompression secondary to multiple perforating vessels that are present in some patients. During our dissections, we observed that the perforating arteries do limit the range of movement of the main trunk of the AICA. These are friable vessels and are torn easily at the parafloccular perforation point without careful AICA manipulation. In addition, we found short perforating vessels from the AICA providing vasa nervorum to the vestibulocochlear and facial nerves before entering the brainstem within a few millimeters from the apparent origin of the nerves. These small vessels are very vulnerable to traction and compression (Fig. 7).

Wang et al. ${ }^{63}$ mentioned that veins can play an important role in vascular compression syndromes and can be the only offending vessels found during microvascular decompression for hemifacial spasm. In our dissections, the veins were generally in proximity to the brainstem surface, especially in the fissures, and had many short and friable tributaries that anchored these vessels to the neuraxis. These features make veins difficult to mobilize and may tempt the surgeon to indiscriminately use bipolar electrocautery. It is important to emphasize that $65 \%$ of the perforating vessels observed in our study were hidden underneath veins, especially by the vein of the cerebellopontine fissure and the vein of the middle cerebellar peduncle (Fig. 8). In addition, we found that the veins draining the deep brainstem and cerebellum in this region emerge in close association to the perforating arteries. These features make the excessive use of bipolar coagulation hazardous, and it is possible that direct tissue injury secondary to heat from coagulation and the loss of blood supply from perforating vessel damage can increase the risk for complications such as hearing loss, facial palsy, difficulty swallowing, diplopia, and ataxia. To decrease the complication rates of posterior fossa surgery, gentle retraction of the cerebellum that avoids the cerebellopontine and horizontal fissures and requires only minimal, judicious, low-power coagulation of the veins might be helpful. ${ }^{63}$

\section{Conclusions}

The cerebellar parafloccular space is a key entry point of many AICA perforating vessels that distribute though the middle cerebellar peduncle and lateral brainstem. These tiny numerous vessels mainly concentrate in the superior cerebellopontine fissure and are generally hidden and intimately related to the venous structures. Some of these vessels enter the brainstem very close to the apparent origin of the CNs of the CPA, at times providing the vasa nervorum to the facial and vestibulocochlear nerves, and are at risk during surgical manipulation. The perforating vessels of the parafloccular space must be identified and protected during surgical intervention for pathologies of the CPA, including tumors, aneurysms, and vascular compression syndromes, in order to decrease morbidity and mortality.

\section{Acknowledgments}

We thank Prof. Mabel Foscolo for technical assistance with the scanning electron microscope. We are also grateful to Megan Foldenauer for artwork assistance and Holly Wagner for editorial assistance. Finally, we express our appreciation to Mr. Guillermo Mangione and Mr. Dean Mueller for their expertise and assistance in preparing the human cadaveric specimens. This study was supported by Motor City Golf Classic Research Grant, Department of Neurosurgery, University of Michigan, 2013 (PI: Luis Savastano).

\section{References}

1. Akar ZC, Dujovny M, Gómez-Tortosa E, Slavin KV, Ausman JI: Microvascular anatomy of the anterior surface of the medulla oblongata and olive. J Neurosurg 82:97-105, 1995

2. Amarenco P, Hauw JJ: [Anatomy of the cerebellar arteries.] Rev Neurol (Paris) 145:267-276, 1989 (Fr)

3. Amarenco P, Hauw JJ: Cerebellar infarction in the territory of the anterior and inferior cerebellar artery. A clinicopathological study of 20 cases. Brain 113:139-155, 1990

4. Amarenco P, Rosengart A, DeWitt LD, Pessin MS, Caplan LR: Anterior inferior cerebellar artery territory infarcts. 
Mechanisms and clinical features. Arch Neurol 50:154-161, 1993

5. Andaluz N, Pensak ML, Zuccarello M: Multiple, peripheral aneurysms of the anterior inferior cerebellar artery. Acta Neurochir (Wien) 147:419-422, 2005

6. Artero JC, Ausman JI, Dujovny M, Mora EO, Umansky F, Diaz FG, et al: Middle cerebral artery reconstruction. Surg Neurol 24:5-11, 1985

7. Bambakidis NC, Manjila S, Dashti S, Tarr R, Megerian CA: Management of anterior inferior cerebellar artery aneurysms: an illustrative case and review of literature. Neurosurg Focus 26(5):E6, 2009

8. Barker FG II, Jannetta PJ, Bissonette DJ, Shields PT, Larkins MV, Jho HD: Microvascular decompression for hemifacial spasm. J Neurosurg 82:201-210, 1995

9. Barley J, Ellis C: Microvascular decompression: a surgical option for refractory hypertension of neurogenic etiology. Expert Rev Cardiovasc Ther 11:629-634, 2013

10. Bonneville F, Sarrazin JL, Marsot-Dupuch K, Iffenecker C, Cordoliani YS, Doyon D, et al: Unusual lesions of the cerebellopontine angle: a segmental approach. Radiographics 21:419-438, 2001

11. Campos-Benitez M, Kaufmann AM: Neurovascular compression findings in hemifacial spasm. J Neurosurg 109:416-420, 2008

12. Camuscu H, Dujovny M, Abd el-Bary T, Beristain X, Viñas FC: Microanatomy of the perforators of the anterior communicating artery complex. Neurol Res 19:577-587, 1997

13. Crosby EC, Humphrey T, Lauer EW: Correlative Anatomy of the Nervous System. New York: Macmillan, 1962

14. David M, Askenasy H: Ataxia and astereognosis of bulbar origin. Brain 60:354-360, 1937

15. de Oliveira JG, Beck J, Seifert V, Teixeira MJ, Raabe A: Assessment of flow in perforating arteries during intracranial aneurysm surgery using intraoperative near-infrared indocyanine green videoangiography. Neurosurgery 62 (6 Suppl 3):1300-1310, 2008

16. Dietrichs E: Clinical manifestation of focal cerebellar disease as related to the organization of neural pathways. Acta Neurol Scand Suppl 188:6-11, 2008

17. Dujovny M, Dujovny N, Gundamraj NR, Misra M: Bipolar coagulation in neurosurgery. Surg Neurol 49:328-332, 1998

18. Dujovny M, Ibe O, Perlin A, Ryder T: Brain retractor systems. Neurol Res 32:675-683, 2010

19. Esmer AF, Sen T, Bilecenoglu B, Tuccar E, Uz A, Karahan ST: Neurovascular relationship between abducens nerve and anterior inferior cerebellar artery. Folia Morphol (Warsz) 69:201-203, 2010

20. Figueiredo EG, Paiva WS, Teixeira MJ: A distal AICA aneurysm. Arq Neuropsiquiatr 67:112-114, 2009

21. Fine AD, Cardoso A, Rhoton AL Jr: Microsurgical anatomy of the extracranial-extradural origin of the posterior inferior cerebellar artery. J Neurosurg 91:645-652, 1999

22. Fukushima K: Roles of the cerebellum in pursuit-vestibular interactions. Cerebellum 2:223-232, 2003

23. Haines SJ, Jannetta PJ, Zorub DS: Microvascular relations of the trigeminal nerve. An anatomical study with clinical correlation. J Neurosurg 52:381-386, 1980

24. Hegarty JL, Jackler RK, Rigby PL, Pitts LH, Cheung SW: Distal anterior inferior cerebellar artery syndrome after acoustic neuroma surgery. Otol Neurotol 23:560-571, 2002

25. Ito M: Neurophysiology of the nodulofloccular system. Rev Neurol (Paris) 149:692-697, 1993

26. Jannetta PJ: Arterial compression of the trigeminal nerve at the pons in patients with trigeminal neuralgia. J Neurosurg 26:159-162, 1967

27. Jannetta PJ, Fletcher LH, Grondziowski PM, Casey KF, Sekula RF Jr: Type 2 diabetes mellitus: A central nervous system etiology. Surg Neurol Int 1:2152-7806, 2010
28. Jo KW, Kong DS, Park K: Microvascular decompression for hemifacial spasm: long-term outcome and prognostic factors, with emphasis on delayed cure. Neurosurg Rev 36:297-302, 2013

29. Kania R, Lot G, Herman P, Tran Ba Huy P: [Vascular complications after acoustic neurinoma surgery.] Ann Otolaryngol Chir Cervicofac 120:94-102, 2003 (Fr)

30. Kase CS, Norrving B, Levine SR, Babikian VL, Chodosh EH, Wolf PA, et al: Cerebellar infarction. Clinical and anatomic observations in 66 cases. Stroke 24:76-83, 1993

31. Kataoka H, Izumi T, Kinoshita S, Kawahara M, Sugie K, Ueno S: Infarction limited to both middle cerebellar peduncles. J Neuroimaging 21:e171-e172, 2011

32. Kawashima M, Rhoton AL Jr, Tanriover N, Ulm AJ, Yasuda A, Fujii K: Microsurgical anatomy of cerebral revascularization. Part II: posterior circulation. J Neurosurg 102:132-147, 2005

33. Kim EY, Park HS, Kim JJ, Lee SC, Ha CK, Park HC: A more basal approach in microvascular decompression for hemifacial spasm: the para-condylar fossa approach. Acta Neurochir (Wien) 143:141-145, 2001

34. Kim HN, Kim YH, Park IY, Kim GR, Chung IH: Variability of the surgical anatomy of the neurovascular complex of the cerebellopontine angle. Ann Otol Rhinol Laryngol 99:288296, 1990

35. Kondoh T, Kurihara E, Kohmura E: Distal anterior inferior cerebellar artery aneurysm occult on magnetic resonance angiography one month prior to rupture-case report. Neurol Med Chir (Tokyo) 43:345-348, 2003

36. Kong DS, Park K: Hemifacial spasm: a neurosurgical perspective. J Korean Neurosurg Soc 42:355-362, 2007

37. Laha RK, Dujovny M, Rao S, Barrionuevo PJ, Bunegin L, Hellstrom HR, et al: Cerebellar retraction: significance and sequelae. Surg Neurol 12:209-215, 1979

38. Liang Q, Shi X, Wang Y, Sun Y, Wang R, Li S: Microvascular decompression for hemifacial spasm: technical notes on pontomedullary sulcus decompression. Acta Neurochir (Wien) 154:1621-1626, 2012

39. Mahmood A, Dujovny M, Torche M, Dragovic L, Ausman JI: Microvascular anatomy of foramen caecum medullae oblongatae. J Neurosurg 75:299-304, 1991

40. Marinković S, Kovacević M, Gibo H, Milisavljević M, Bumbasirević L: The anatomical basis for the cerebellar infarcts. Surg Neurol 44:450-461, 1995

41. Martin RG, Grant JL, Peace D, Theiss C, Rhoton AL Jr: Microsurgical relationships of the anterior inferior cerebellar artery and the facial-vestibulocochlear nerve complex. Neurosurgery 6:483-507, 1980

42. Matsushima T, Inoue T, Natori Y, Fukui M, de Oliveira E, Rhoton AL Jr: [Microsurgical anatomy of the region near the porus acusticus internus; arteries around the facial and acoustic nerves bundle.] No Shinkei Geka 20:409-415, 1992 (Jpn)

43. McDermott AL, Dutt SN, Irving RM, Pahor AL, Chavda SV: Anterior inferior cerebellar artery syndrome: fact or fiction. Clin Otolaryngol Allied Sci 28:75-80, 2003

44. Mercier PH, Brassier G, Fournier HD, Picquet J, Papon X, Lasjaunias P: Vascular microanatomy of the pontomedullary junction, posterior inferior cerebellar arteries, and the lateral spinal arteries. Interv Neuroradiol 14:49-58, 2008

45. Nagatani T, Inao S, Suzuki Y, Yoshida J: Perforating branches from offending arteries in hemifacial spasm: anatomical correlation with vertebrobasilar configuration. J Neurol Neurosurg Psychiatry 67:73-77, 1999

46. Naidich TP, Duvernoy HM, Delman BN, Sorensen AG, Kollias SS, Haacke EM: Vascularization of the cerebellum and the brain stem, in Duvernoy's Atlas of the Human Brain Stem and Cerebellum. Vienna: Springer, 2009, pp 159-217

47. Naidich TP, Kricheff II, George AE, Lin JP: The normal an- 
terior inferior cerebellar artery. Anatomic-radiographic correlation with emphasis on the lateral projection. Radiology 119:355-373, 1976

48. Ohue S, Fukushima T, Friedman AH, Kumon Y, Ohnishi T: Retrosigmoid suprafloccular transhorizontal fissure approach for resection of brainstem cavernous malformation. Neurosurgery 66 (6 Suppl Operative):306-313, 2010

49. Pai BS, Varma RG, Kulkarni RN, Nirmala S, Manjunath LC, Rakshith S: Microsurgical anatomy of the posterior circulation. Neurol India 55:31-41, 2007

50. Peluso JP, van Rooij WJ, Sluzewski M, Beute GN: Distal aneurysms of cerebellar arteries: incidence, clinical presentation, and outcome of endovascular parent vessel occlusion. AJNR Am J Neuroradiol 28:1573-1578, 2007

51. Perrini P, Tiezzi G, Castagna M, Vannozzi R: Three-dimensional microsurgical anatomy of cerebellar peduncles. Neurosurg Rev 36:215-225, 2013

52. Rhoton AL Jr: The cerebellopontine angle and posterior fossa cranial nerves by the retrosigmoid approach. Neurosurgery 47 (3 Suppl):S93-S129, 2000

53. Rodríguez-Hernández A, Rhoton AL Jr, Lawton MT: Segmental anatomy of cerebellar arteries: a proposed nomenclature. Laboratory investigation. J Neurosurg 115:387-397, 2011

54. Roquer J, Lorenzo JL, Pou A: The anterior inferior cerebellar artery infarcts: a clinical-magnetic resonance imaging study. Acta Neurol Scand 97:225-230, 1998

55. Rosenørn J, Diemer NH: Reduction of regional cerebral blood flow during brain retraction pressure in the rat. J Neurosurg 56:826-829, 1982

56. Samii M, Gerganov VM: Surgery of extra-axial tumors of the cerebral base. Neurosurgery 62 (6 Suppl 3):1153-1168, 2008

57. Santillan A, Gobin YP, Patsalides A, Riina HA, Rosengart A, Stieg PE: Endovascular management of distal anterior inferior cerebellar artery aneurysms: Report of two cases and review of the literature. Surg Neurol Int 2:95, 2011

58. Sarkar A, Link MJ: Distal anterior inferior cerebellar artery aneurysm masquerading as a cerebellopontine angle tumor: case report and review of literature. Skull Base 14:101-107, 2004

59. Shrontz C, Dujovny M, Ausman JI, Diaz FG, Pearce JE, Ber- man SK, et al: Surgical anatomy of the arteries of the posterior fossa. J Neurosurg 65:540-544, 1986

60. Sindou MP, Polo G, Fischer C, Vial C: Neurovascular conflict and hemifacial spasm. Suppl Clin Neurophysiol 58:274281,2006

61. Sosa P, Dujovny M, Cremaschi F, Onyekachi I, Noressia S: [Voluntary exile of Pio del Rio Hortega in Buenos Aires, Argentina.] Neurocirugia-Neurocirugia 22:31-55, 2013 (Span)

62. Tekkök IH, Süzer T, Erbengi A: Non-acoustic tumors of the cerebellopontine angle. Neurosurg Rev 15:117-123, 1992

63. Wang X, Thirumala PD, Shah A, Gardner P, Habeych M, Crammond D, et al: The role of vein in microvascular decompression for hemifacial spasm: a clinical analysis of 15 cases. Neurol Res 35:389-394, 2013

64. Yaşargil MG: Microsurgical anatomy of the basal cisterns and vessels of the brain, diagnostic studies, general operative techniques and pathological considerations of the intracranial aneurysms, in Microneurosurgery. New York: Thieme, 1984

\section{Disclosure}

The authors report no conflict of interest concerning the materials or methods used in this study or the findings specified in this paper. This article is original and has not been previously published and is not under consideration for publication elsewhere.

\section{Author Contributions}

Conception and design: Dujovny, Sosa, Savastano. Acquisition of data: Savastano, Sosa, Dujovny. Analysis and interpretation of data: all authors. Drafting the article: Savastano, Sosa. Critically revising the article: Savastano, Sosa, Cremaschi, Dujovny. Reviewed submitted version of manuscript: all authors. Approved the final version of the manuscript on behalf of all authors: Savastano. Study supervision: Dujovny, Savastano.

\section{Correspondence}

Luis E. Savastano, Department of Neurosurgery, University of Michigan, 1500 E. Medical Center Dr., Rm. 3552 TC, Ann Arbor, MI 48109-5338. email: 1savasta@med.umich.edu. 